\title{
ANÁLISE DA BIODIVERSIDADE DE MICRORGANISMOS DO SOLO PRODUTORES DE AMILASE NA MICRO-REGIÃO DE ARAÇATUBA/SP.
}

\section{Muriel Tábatha Junqueira ${ }^{1}$ \\ Eliane Patrícia Cervelatti ${ }^{2}$}

RESUMO: O Brasil apresenta uma vasta biodiversidade de microrganismos presentes no solo com potencial uso biotecnológico, a maioria ainda não identificada. O mau uso do solo observado nos últimos anos tem contribuído para uma redução na biodiversidade dos microrganismos presentes no solo, o que revela a necessidade do desenvolvimento de estratégias para preservação e exploração do patrimônio genético microbiano presente no solo. Visando colaborar nesse sentido, o presente trabalho teve por objetivo detectar a presença de microrganismos produtores da enzima amilase em amostras de solo coletadas em diferentes áreas de conservação ambiental. Para tanto, as amostras de solo foram diluídas em solução salina e alíquotas de $0,2 \mathrm{~mL}$ das diluições serão cultivadas em meio de cultura ágar-amido. Após o crescimento, a detecção da atividade enzimática foi feita pela adição de solução de iodo ao meio de cultura, o que revelou a presença de regiões mais claras ao redor de alguns microrganismos, as quais correspondem aos locais onde a enzima degradou o amido (quanto maior a área clara ao redor do microrganismo, maior é o nível de produção enzimática). A análise dos dados obtidos no presente trabalho demonstrou a existência microrganismos secretores da enzima amilase nas diferentes regiões analisadas. No entanto, microrganismos coletados em solo de áreas com maior biodiversidade apresentaram maiores índices de atividade enzimática.

${ }^{1}$ Graduanda em Ciências Biológicas - UniSalesiano-Araçatuba/SP. tabathajunqueira@hotmail.com

${ }^{2}$ Bióloga, Doutora em Genética. Docente - UniSalesiano-Araçatuba/SP. ecervelatti@hotmail.com

Palavras-chave: Amilase. Microrganismos. Solo. 


\subsection{INTRODUÇÃO}

Apesar de sua grande importância na manutenção da biosfera, estima-se que menos de $10 \%$ dos microrganismos existentes no planeta tenham sido caracterizados e descritos (Staley, 1998).

Do ponto de vista histórico, microrganismos cultiváveis do solo têm sido uma fonte inestimável para a produção de compostos naturais com atividade biológicas importantes para a humanidade (Bull et al., 2000). Durante os últimos 50 anos, produtos derivados de metabólitos secundários têm sido usados nas áreas médica, industrial e agrícola, como os antibióticos, drogas anti-carcinogênicas, anti-fúngicos, agentes imunossupressores, probióticos; enzimas e polímeros para aplicações industriais e tecnológicas, herbicidas, inseticidas, promotores de crescimento, entre outros. Outras enzimas microbianas são importantes para pesquisa acadêmica e desenvolvimento de aplicações biotecnológicas, incluindo as enzimas de restrição e polimerases de ácidos nucléicos, as quais são rotineiramente utilizadas na tecnologia do DNA recombinante (Oliveira et al., 2006).

Dentre as enzimas microbianas, cabe salientar que as amilases estão entre as mais importantes e são de grande interesse na biotecnologia atual, devido à sua ampla aplicação em vários campos, incluindo a química clínica, produção de medicamentos, indústria têxtil, produção de papel, indústria de alimentos, liquefação do amido e produção de açúcar (Pandey et al., 2000).

Tradicionalmente, compostos com atividade biológica têm sido acessados por métodos envolvendo isolamento e cultivo dos organismos a partir das amostras ambientais, principalmente solo. Isolados e/ou produtos de fermentação passam por um processo de triagem para as atividades desejadas. A maioria das enzimas utilizadas industrialmente tem sido descoberta desta maneira (Oliveira et al., 2006).

A pesquisa embasou-se em dois objetivos: o Geral (Detectar a presença de microrganismos do solo produtores da enzima amilase) e o Específico (Comparar a biodiversidade de microrganismos produtores de amilase em diferentes áreas de conservação ambiental na micro-região de Araçatuba/SP. E comparar os níveis de produção de amilase apresentados pelos microrganismos obtidos). 
Diante deste contexto, a análise da biodiversidade de microrganismos produtores da amilase presentes no solo é de suma importância para caracterização e preservação do patrimônio genético, bem como para a detecção de novos de microrganismos para produção desta enzima.

\subsection{MATERIAL E MÉTODOS}

A coleta do material utilizado no presente trabalho foi feita em diferentes áreas de conservação ambiental na micro-região de Araçatuba/SP.

As amostras de solo analisadas foram coletadas a partir de camadas do solo do Horizonte $\mathrm{O}(0,0-5,0 \mathrm{~cm})$. Em seguida, as amostras foram colocadas em frascos autoclavados e transportadas ao laboratório. Posteriormente, foram feitas diluições seriadas em solução salina autoclavada, utilizando-se inicialmente $1 \mathrm{~g}$ de solo de cada Horizonte. Alíquotas de 0,2 $\mathrm{mL}$ de cada diluição foram plaqueadas nos meios de cultura ágar-amido pela técnica de semeadura em superfície. Em seguida, as placas de Petri foram mantidas à $28^{\circ} \mathrm{C}$ durante $72 \mathrm{~h}$. Após esse período, o número de colônias foi contado e o número de microrganismos no solo estimado, considerando as devidas diluições e o resultado apresentado em Unidades Formadoras de Colônia UFC / g de solo.

A detecção da atividade da amilase foi realizada conforme descrito por OLIVEIRA et al (2006), pela adição de uma solução de iodo capaz de corar o amido de azul. As regiões onde esse polissacarídeo foi degradado pela amilase não se coram, evidenciando a atividades dessa enzima na forma de um halo incolor.

A estimativa da produção da amilase consistiu na medida de dois diâmetros ortogonais da colônia e do respectivo halo. A atividade enzimática foi estimada semiquantitativamente, usando um índice enzimático (IE) que expressa a relação do diâmetro médio da colônia pelo diâmetro médio do halo. Deste modo, os isolados com maior índice foram os que possuírem maior atividade enzimática. Após $72 \mathrm{~h}$ a 25ㄷ de cultivo no meio Agar-amido, o índice de atividade enzimática (IE) foi determinado de acordo com o método de OLIVEIRA et al, (2006). Esse índice é estimado pela seguinte fórmula: $\mathrm{IE}=(\mathrm{DC}+\mathrm{DH}) / \mathrm{DC}$, onde $\mathrm{DC}=$ diâmetro da colônia e $\mathrm{DH}=$ diâmetro do halo. 


\section{Resultados}

Os resultados obtidos nas diferentes áreas de coleta, relativos à melhor diluição para trabalho e produção enzimática estão descritos abaixo.

\section{Área 1: Parque Ecológico de Araçatuba (Parque do Peba).}

Características do Solo representadas na figura 01: amostras de solo superficiais, com colorações distintas (um escuro devido à presença de serapilheira e outra clara ausência da mesma).
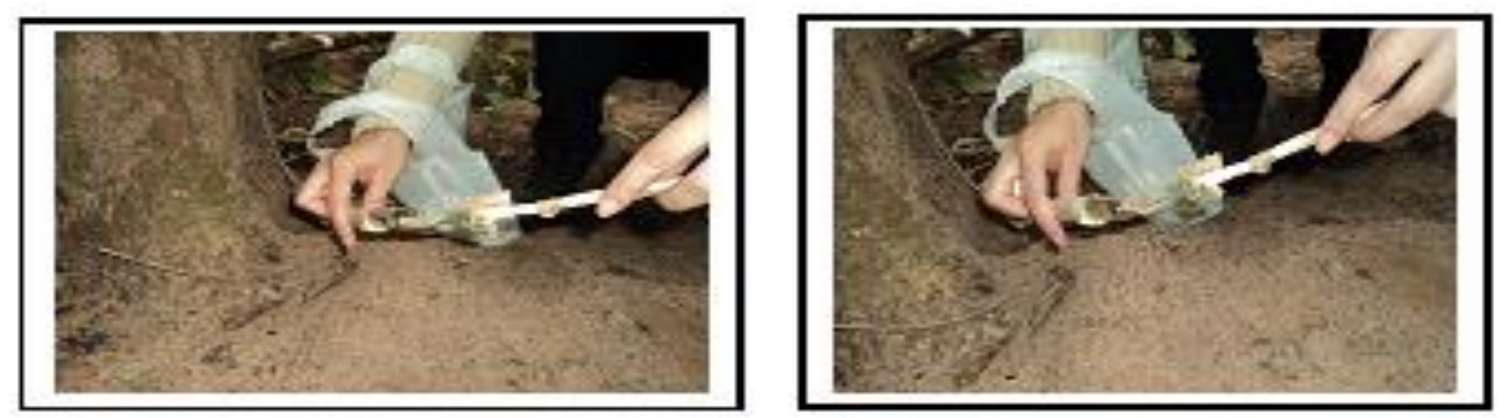

FIGURA 01: coleta do solo superficial no parque Ecológico de Araçatuba (obs: a matéria orgânica presente na superfície - serapilheira - foi previamente removida para coleta do material a ser analisado).

Após o processo de diluição seriada (até $10^{-7}$ ), as amostras foram plaqueadas em placa de Petri contendo meio de cultivo Ágar-amido e mantidas a $28^{\circ} \mathrm{C}$ por $72 \mathrm{~h}$. A análise dos dados mostrou que a diluição $10^{-4}$ apresenta melhores condições de crescimento para obtenção de colônias de microrganismos isolados.

Os microrganismos que cresceram isoladamente no experimento acima descrito foram devidamente identificados e transferidos para outra placa de Petri contendo meio de cultivo Ágar-amido e mantidos a $28^{\circ} \mathrm{C}$ por $24 \mathrm{~h}$ para análise da produção da enzima amilase (figura 02). Ao todo, dezesseis colônias foram transferidas, sendo 15 bactérias e 01 fungo. 


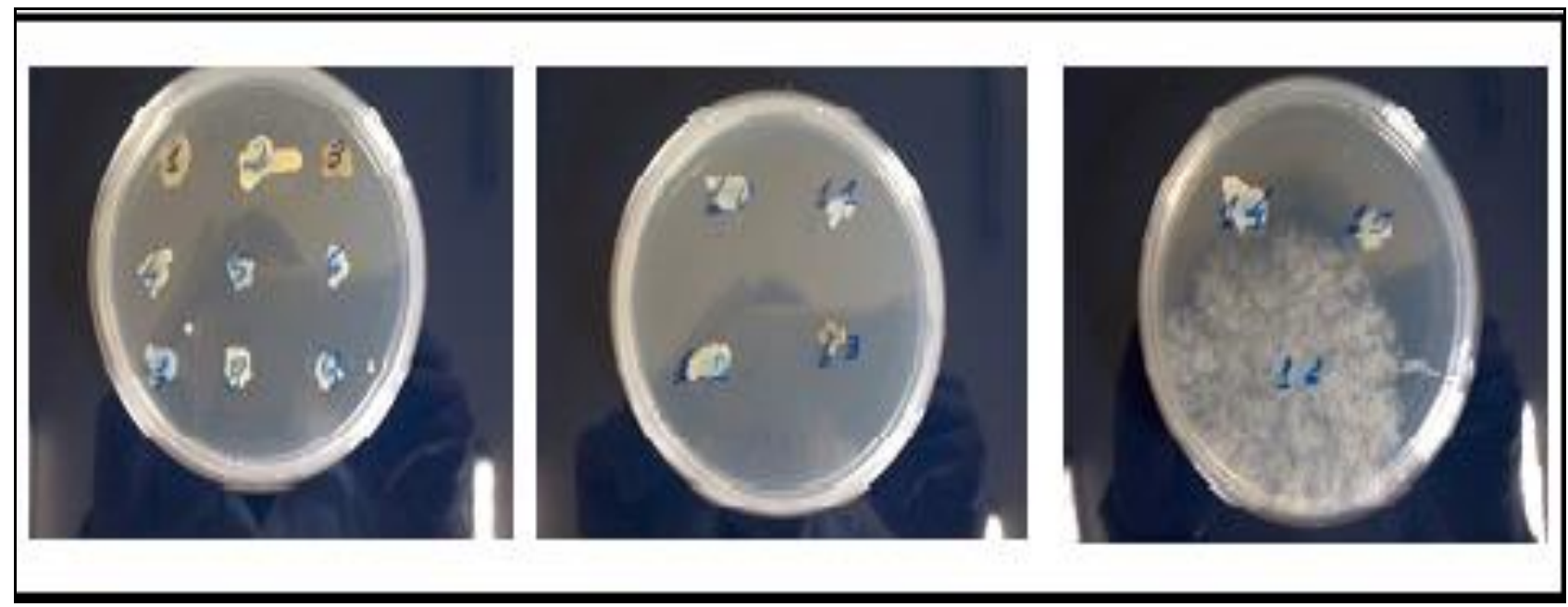

FIGURA 02: Placas de Petri contendo meio de cultivo Ágar-amido mostrando o crescimento das 16 colônias isoladas de microrganismos provenientes do Parque Ecológico de Araçatuba.

A análise da produção da enzima amilase pelos microrganismos obtidos foi feita pela adição de solução de iodo $0,1 \mathrm{~N}$ ao meio de cultivo. A solução de iodo é capaz de corar o amido de azul, portanto, as regiões onde esse polissacarídeo foi degradado pela amilase não se coram, evidenciando a atividades dessa enzima na forma de um halo incolor (figura 03).

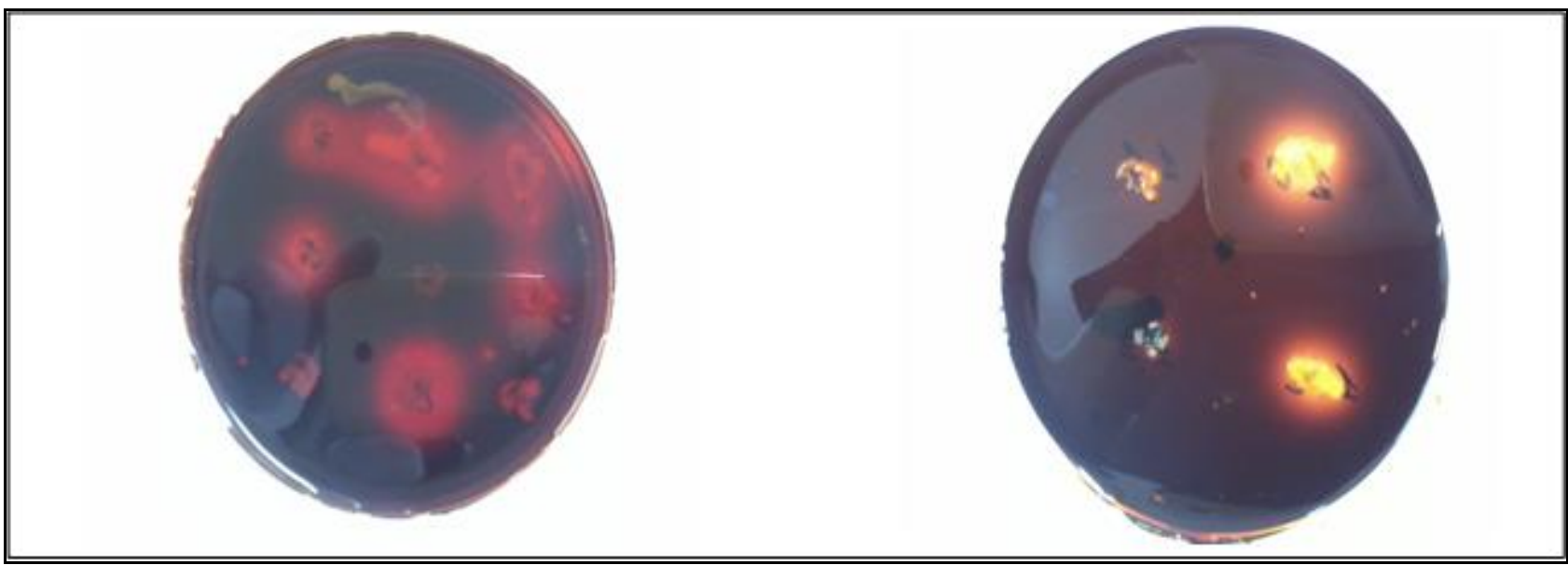

FIGURA 03: Halo de degradação do amido pela enzima amilase (regiões claras ao redor das colônias) evidenciado pela adição de solução de iodo as placas apresentadas na figura 03 . 
Conforme observado na figura 03 , as colônias $1,2,3,4,6,8,10,12,14$ e 16 produziram e secretaram a enzima amilase. Esses microrganismos foram novamente cultivados e então submetidos a avaliação da produção enzimática. A partir dos dados obtidos foi calculado o índice de atividade enzimática, os quais estão apresentados na tabela 01.

TABELA 01: Índice de atividade enzimática de microrganismos provenientes do solo do Parque Ecológico de Araçatuba (média obtida a partir de um experimento feito em triplicata).

\begin{tabular}{|c|c|c|c|}
\hline Microrganismos & DC & DH & IE \\
\hline 1 & 1,8 & 3,1 & 2,72 \\
\hline 2 & 1,9 & 2,9 & 2,53 \\
\hline 3 & 1,6 & 2,9 & 2,81 \\
\hline 4 & 1,7 & 1,9 & 2,12 \\
\hline 6 & 1,8 & 2,2 & 2,22 \\
\hline 8 & 2 & 3 & 2,5 \\
\hline 10 & 2 & 2,2 & 2,1 \\
\hline 12 & 2 & 1,7 & 1,85 \\
\hline 14 & 2,2 & 3,7 & 2,68 \\
\hline 16 & 2,1 & 3,1 & 2,48 \\
\hline
\end{tabular}

O índice de atividade enzimática foi obtido através da formula: IE = (DC+DH) /DC.

IE = índice de atividade enzimática.

DC = diâmetro da colônia.

$\mathrm{DH}=$ diâmetro do halo de degradação enzimática.

Os resultados apresentados na tabela 01 demonstram que todos os microrganismos isolados produziram e secretaram a enzima amilase. Na maioria dos 
casos, o índice foi superior a 2,0 sendo que apenas no caso da colônia 12 esse valor se mostrou inferior.

\section{Área 2: Pequena Mata próxima a empresa WS.}

Características do solo (Figura: 04): o solo analisado se encontra ao lado de uma APP que fica no bairro rural denominado Prata, ao lado de uma propriedade rural, com pouca serapilheira, arenoso e seco, com aspecto empobrecido a primeira vista.

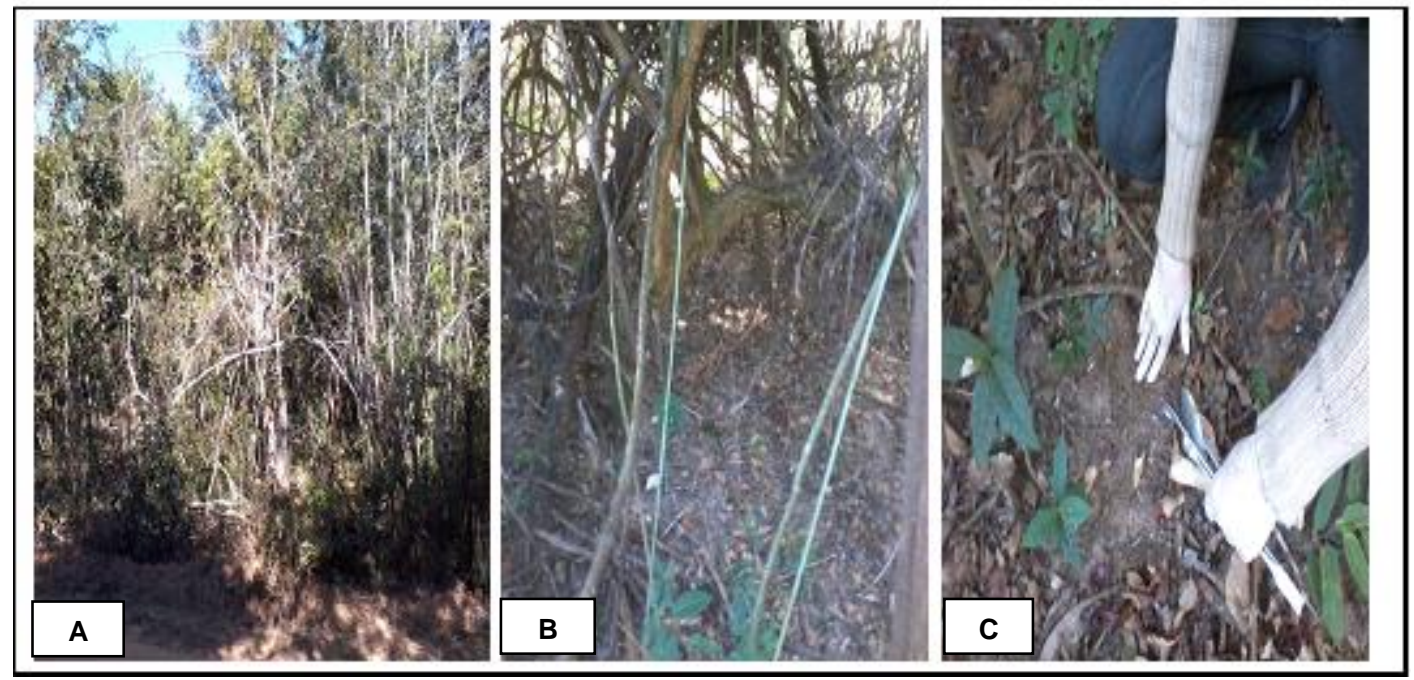

FIGURA 04: A - Características ambientais da área da coleta. B e C - Local onde as amostras de solo foram obtidas.

Após o processo de diluição seriada até $10^{-7}$, as amostras foram plaqueadas em placa de Petri contendo meio de cultivo Ágar-amido e mantidas a $28^{\circ} \mathrm{C}$ por $72 \mathrm{~h}$. A análise dos dados mostrou que a diluição $10^{-3}$ apresenta melhores condições de crescimento para obtenção de colônias de microrganismos isolados (figura 05). 

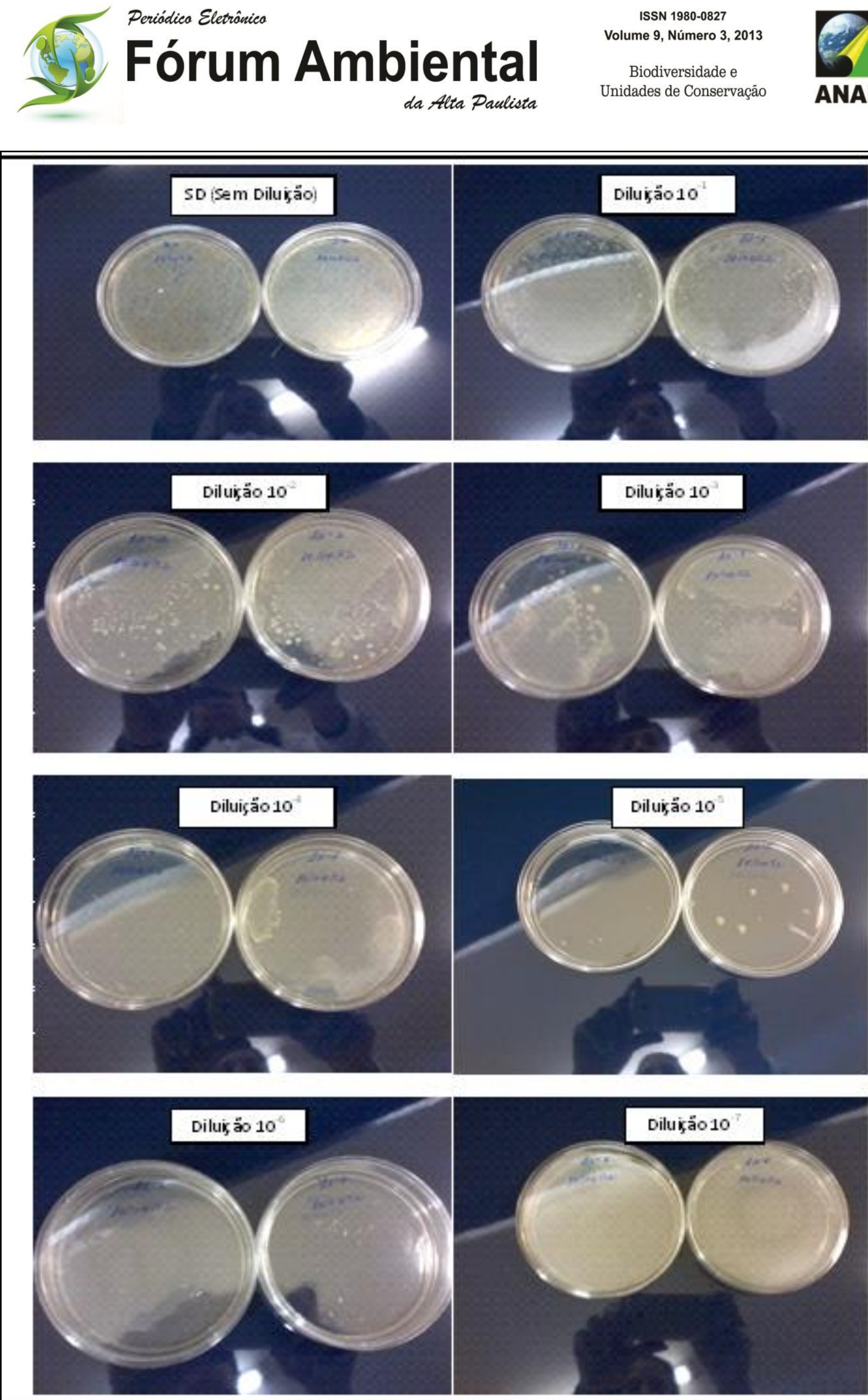
FIGURA 05: Placas de Petri contendo meio de cultivo Ágar-amido mostrando os resultados obtidos na diluição seriada da amostra de solo oriunda do segundo campo de coleta.

Os microrganismos que cresceram isoladamente foram devidamente identificados e transferidos para outra placa de Petri contendo meio de cultivo Ágar-amido e mantidos a $28^{\circ} \mathrm{C}$ por $24 \mathrm{~h}$ para análise da produção da enzima amilase (figura 06). Ao todo, 7 colônias foram transferidas, sendo 6 bactérias e 1 fungo.

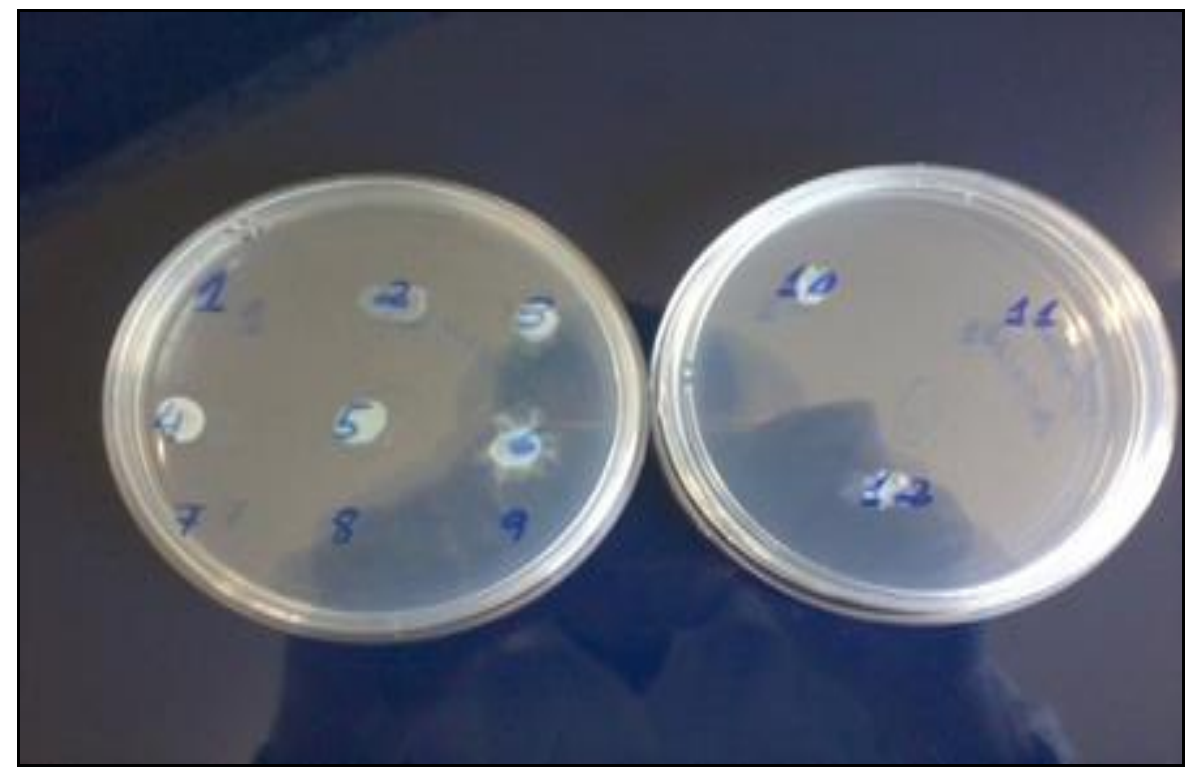

FIGURA 06: Placas de Petri contendo meio de cultivo Ágar-amido mostrando o crescimento de 7 colônias isoladas de microrganismos provenientes da pequena Mata próxima a empresa WS.

Conforme evidenciado pela figura 06 , os microrganismos $1,7,8,9$ e 11 não se desenvolveram.

A próxima etapa da analise de produção da enzima amilase, foi feita pela adição de solução de iodo $0,1 \mathrm{~N}$ ao meio de cultivo, evidenciando o halo de degradação enzimática (figura 07). 


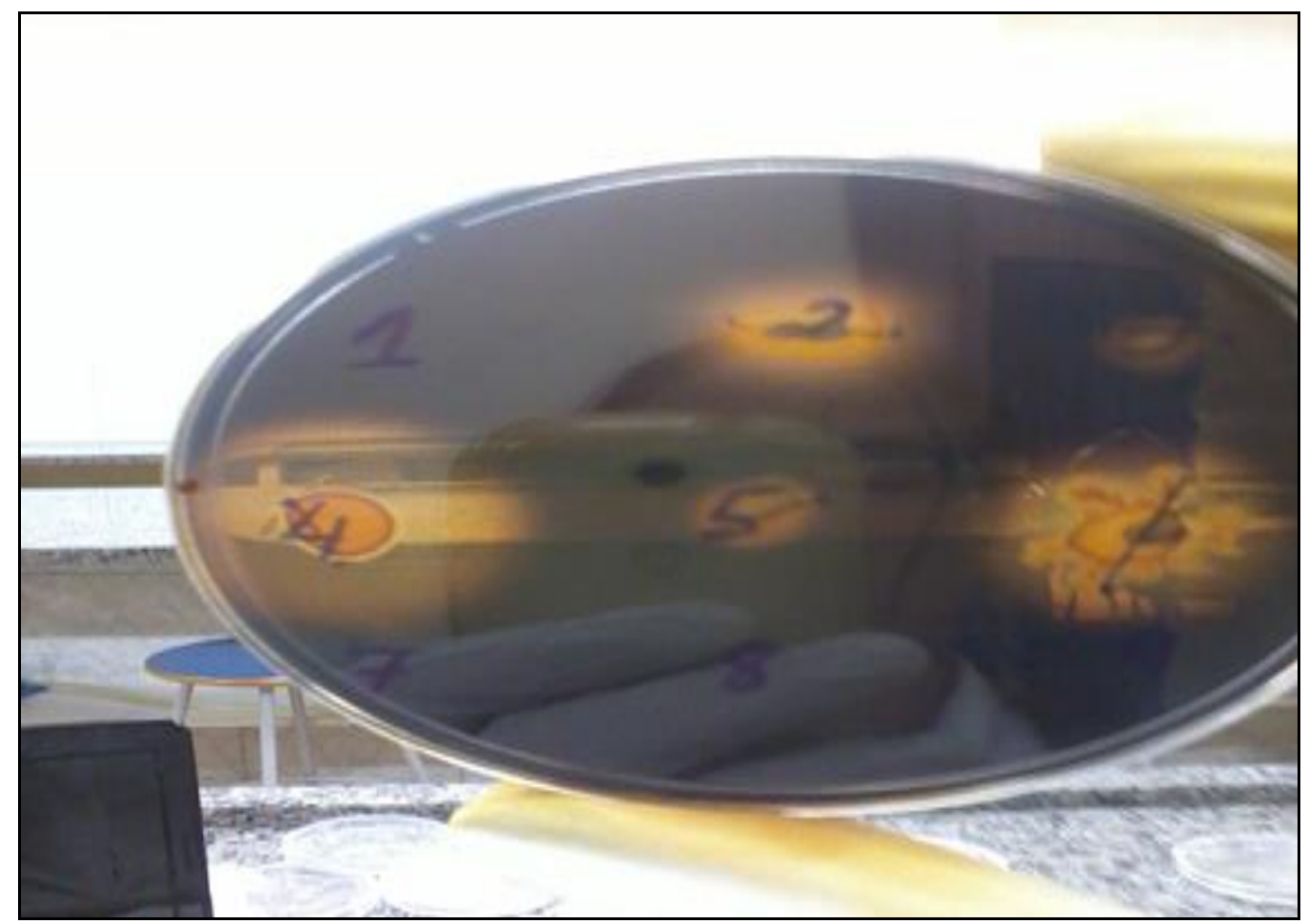

FIGURA 07: Halo de degradação do amido pela enzima amilase (regiões claras ao redor das colônias) evidenciado pela adição de solução de iodo às placas apresentadas na figura 06.

Conforme observado na figura 07 , as colônias 2, 4 e 6 produziram e secretaram a enzima amilase. Esses microrganismos foram novamente cultivados e então submetidos a avaliação da produção enzimática. A partir dos dados obtidos foi calculado o índice de atividade enzimática, os quais estão apresentados na tabela 02.

TABELA 02: Índice de atividade enzimática de microrganismos provenientes do solo da Mata de Preservação perto da empresa WS.

\begin{tabular}{|c|c|c|c|}
\hline Microrganismos & DC & DH & IE \\
\hline 2 & 2 & 2,1 & 2,05 \\
\hline 3 & 1,9 & $\tilde{\mathbf{N}}$ & $*$ \\
\hline 4 & 1,9 & 3,6 & 2,09 \\
\hline 5 & 2 & $\tilde{\mathbf{N}}$ & $*$ \\
\hline
\end{tabular}




\begin{tabular}{|c|c|c|c|}
\hline 6 & 2,5 & 3 & 2,2 \\
\hline 10 & 1,7 & $\tilde{\mathbf{N}}$ & $*$ \\
\hline 12 & 1,2 & $\tilde{\mathbf{N}}$ & $*$ \\
\hline
\end{tabular}

ñ - não secretou amilase.

*Como não houve secreção da enzima, não foi feito calculo do índice de atividade enzimática.

O índice de atividade enzimática foi obtido através da formula: IE = (DC+DH) /DC.

$\mathrm{IE}=$ índice de atividade enzimática.

$\mathrm{DC}=$ diâmetro da colônia.

$\mathrm{DH}=$ diâmetro do halo de degradação enzimática.

Os resultados apresentados na tabela 02 demonstram que apenas 03 dos 07 microrganismos isolados produziram e secretaram a enzima amilase, todos com índice de atividade enzimática acima de 2,0. Os demais microrganismos produziram a enzima amilase apenas para o seu consumo.

\section{Área 3: Mata Ciliar próxima ao Centro Universitário Católico Salesiano Auxilium - Araçatuba SP.}

Características do solo: o solo analisado apresentava muita serapilheira e coloração um pouco escuro, apresentando sofrer queimadas (fica próximo a uma área de plantação de cana - de - açúcar). 


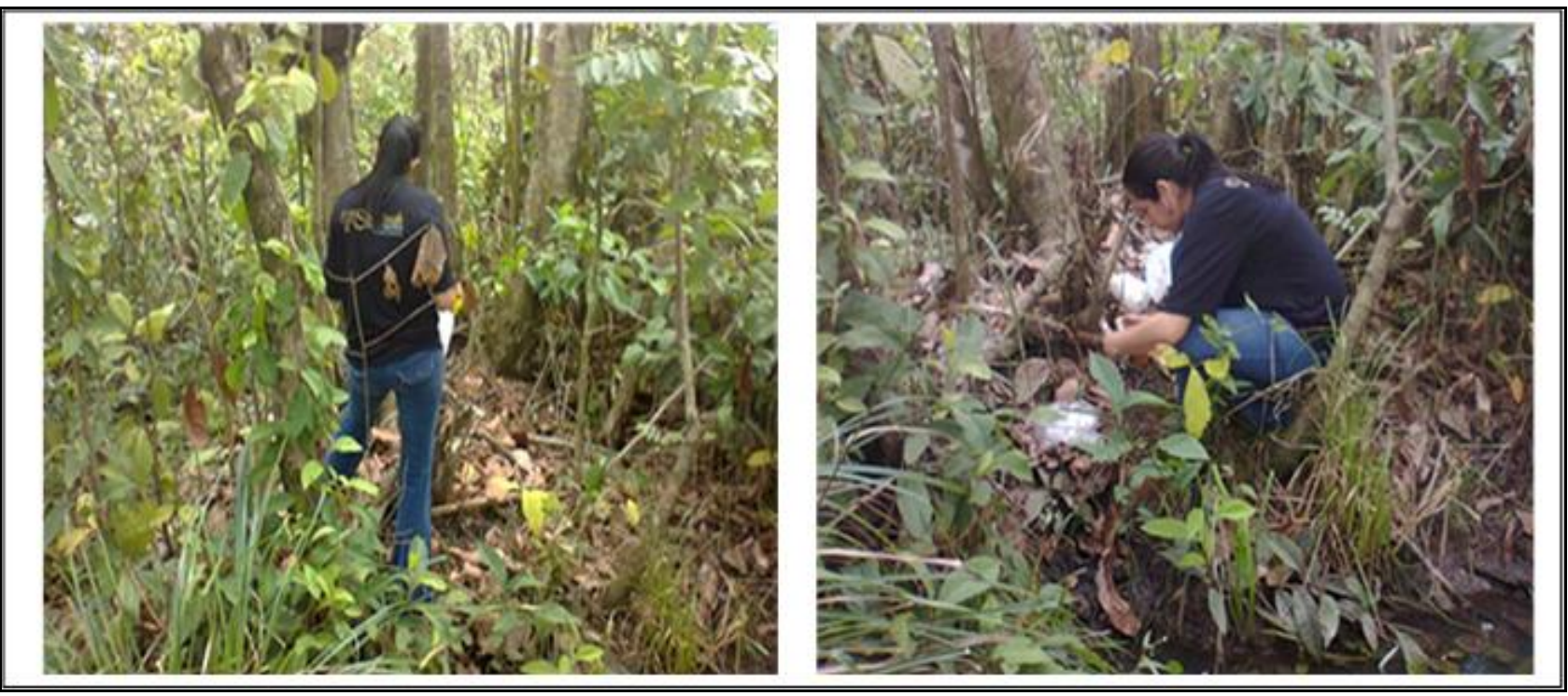

FIGURA 08: local de coleta da amostra de solo com muita serapilheira como características peculiares de queimadas, pois o solo apresentava- se muito escuro, assim como os troncos das árvores presentes.

O processo de diluição seriada e cultivo das amostras foram feitos conforme descrito para as demais áreas de coleta. A análise dos dados mostrou que a diluição $10^{-3}$ apresenta melhores condições de crescimento para obtenção de colônias de microrganismos isolados (figura 09). 


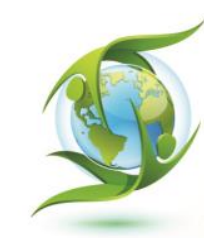

ISSN 1980-0827

Fórum Ambiental

da Alta Paulista

Volume 9, Número 3, 2013

Biodiversidade e

Unidades de Conservação
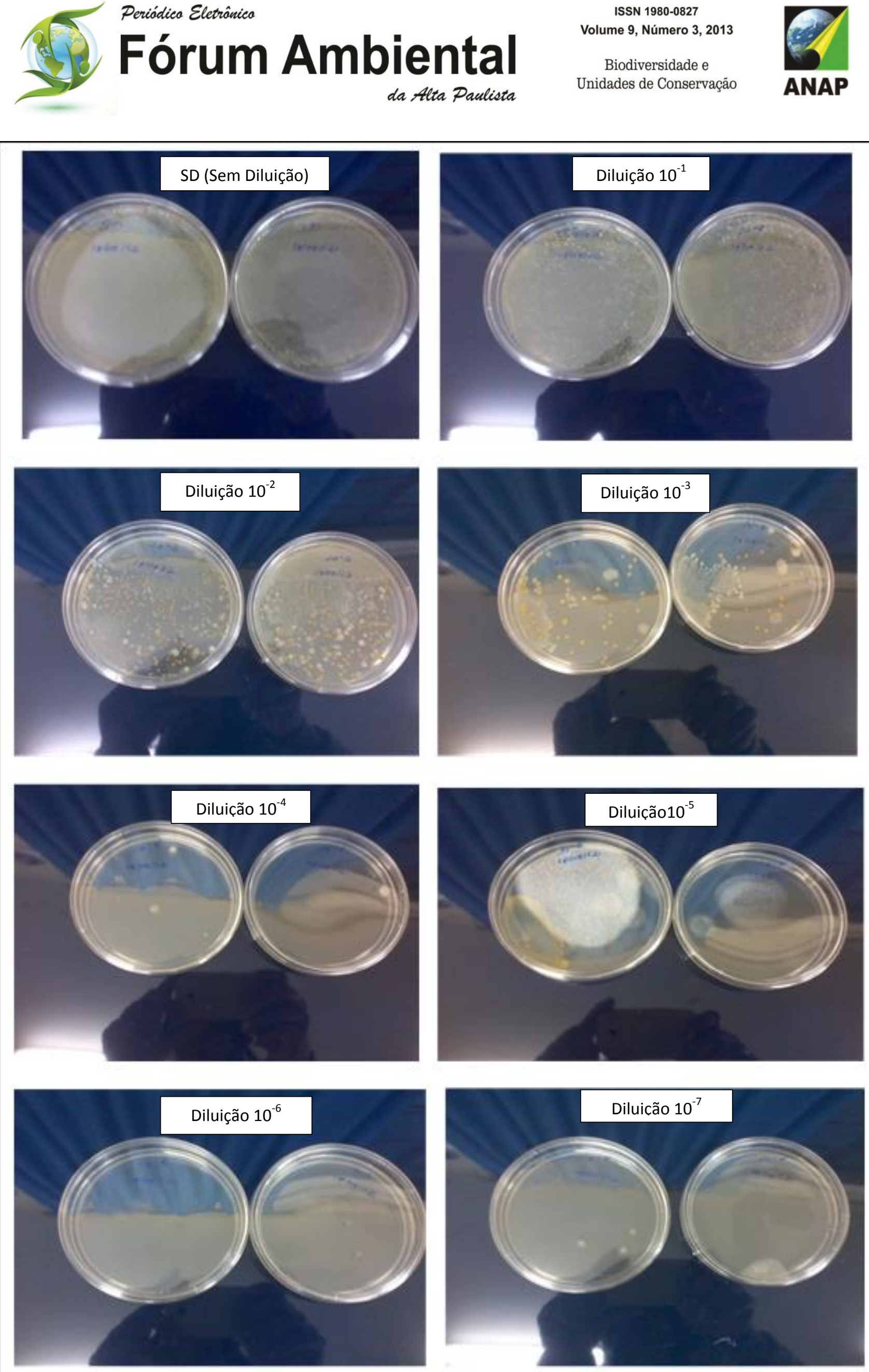
FIGURA 09: Placas de Petri contendo meio de cultivo Ágar-amido mostrando os resultados obtidos na diluição seriada.

Os microrganismos que cresceram isoladamente foram devidamente identificados e transferidos para outra placa de Petri contendo meio de cultivo Ágar-amido e mantidos a $28^{\circ} \mathrm{C}$ por $24 \mathrm{~h}$ para análise da produção da enzima amilase (figura 10). Ao todo, 23 colônias foram transferidas, sendo 20 bactérias e 03 fungos.

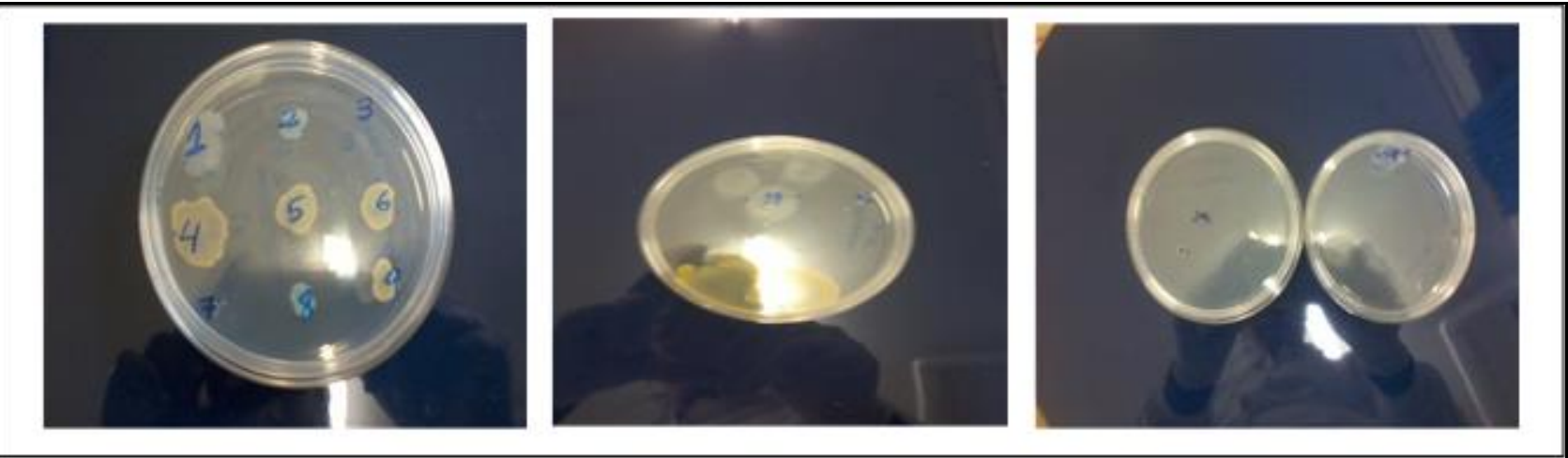

FIGURA 10: Placas de Petri contendo meio de cultivo Ágar-amido mostrando o crescimento da Mata Ciliar atrás do Campus do UniSalesiano, as colônias 3, 7, 14, 20 e 23 não se desenvolveram.

A produção da enzima amilase foi evidenciada pela adição de solução de iodo $0,1 \mathrm{~N}$ ao meio de cultivo (figura 11).

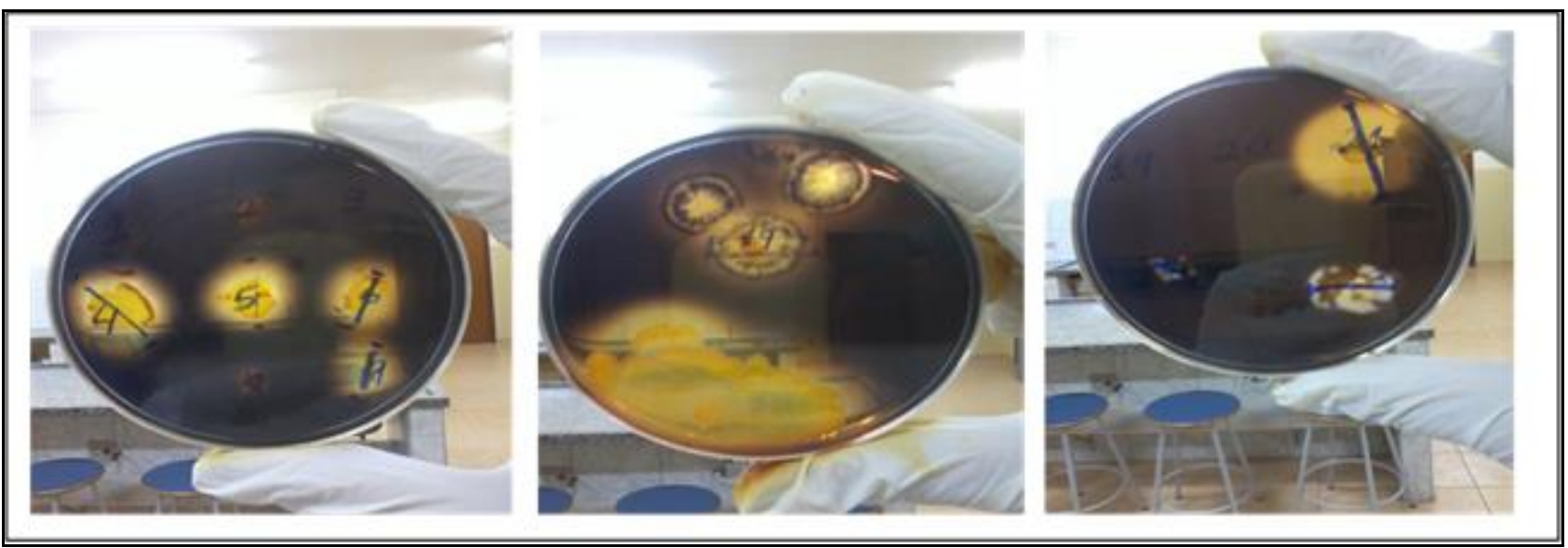

FIGURA 11: Halo de degradação do amido pela enzima amilase (regiões claras ao redor das colônias) evidenciado pela adição de solução de iodo às placas apresentadas na figura 10. 
Conforme observado na figura 11, as colônias 4, 5, 6, 9, 16 e 21 produziram e secretaram a enzima amilase. Esses microrganismos foram novamente cultivados e então submetidos a avaliação da produção enzimática. A partir dos dados obtidos foi calculado o índice de atividade enzimática, os quais estão apresentados na tabela 03.

Tabela 03: Índice de atividade enzimática de microrganismos provenientes do solo da Mata Ciliar, próxima ao Centro Universitário Católico Salesiano Auxilium - Araçatuba SP.

\begin{tabular}{|c|c|c|c|}
\hline Microrganismos & DC & $\mathrm{DH}$ & IE \\
\hline 1 & 2,7 & $\tilde{\mathbf{N}}$ & * \\
\hline 2 & 1,9 & $\tilde{\mathbf{N}}$ & * \\
\hline 4 & 3 & 3,4 & 2,13 \\
\hline 5 & 2,3 & 2,7 & 2,17 \\
\hline 6 & 1,8 & 2 & 2,11 \\
\hline 8 & 2 & $\tilde{\mathbf{N}}$ & * \\
\hline 9 & 2 & 2,5 & 2,25 \\
\hline 10 & 2 & $\tilde{\mathbf{N}}$ & * \\
\hline 11 & 1,6 & $\tilde{\mathbf{N}}$ & * \\
\hline 12 & 1,7 & $\tilde{\mathbf{N}}$ & * \\
\hline 13 & 1,6 & $\tilde{\mathbf{N}}$ & * \\
\hline 15 & 2 & $\tilde{\mathbf{N}}$ & * \\
\hline 16 & 1,3 & 2,3 & 2,77 \\
\hline 17 & 1,9 & $\tilde{\mathbf{N}}$ & * \\
\hline 18 & 1,9 & $\tilde{\mathbf{N}}$ & * \\
\hline
\end{tabular}




\begin{tabular}{|c|c|c|c|}
\hline 19 & 2 & $\tilde{\mathbf{N}}$ & $*$ \\
\hline 21 & 1,9 & 3,6 & 2,9 \\
\hline 22 & 1,7 & $\tilde{\mathbf{N}}$ & $*$ \\
\hline
\end{tabular}

ñ - não secretou amilase.

*Como não houve secreção da enzima, não foi feito o calculo do índice de atividade enzimática.

O índice de atividade enzimática foi obtido através da formula: IE $=(D C+D H) / D C$.

$\mathrm{IE}=$ índice de atividade enzimática.

$\mathrm{DC}=$ diâmetro da colônia .

$\mathrm{DH}$ = diâmetro do halo de degradação enzimática.

Os resultados apresentados na tabela 03 demonstram que apenas 06 dos 18 microrganismos isolados produziram e secretaram a enzima amilase, com índice de atividade enzimática superior a 2,0. Os demais microrganismos produziram a enzima apenas para o seu desenvolvimento.

\subsection{CONCLUSÃO E DISCUSSÃO}

O solo é onde se encontra uma grande variedade de microrganismo. Tanto fatores intrínsecos, como o pH do próprio solo, como os extrínsecos relacionados ao clima e a temperatura, influenciam na quantidade e na atividade desses microrganismos presentes nesse ambiente. Devido a versatilidade de adaptação desses microrganismos em relação a mudanças ambientais, os mesmo são encontrados no solo, que ocasionam a interatividade entre microrganismos, estrutura e matéria orgânica desse ambiente. Quanto maior a quantidade de matéria orgânica presente no solo, maior o índice de microrganismos que contribuem para a qualidade desse ambiente (MOREIRA \& SIQUEIRA, 2006). 
Os microrganismos do solo como bactérias e fungos degradam a matéria orgânica, através da secreção de enzimas (Marciano, 2009). Essas enzimas hidrolisam e oxidam a matéria orgânica, tornando - as alimentos para muitos organismos (PRIMAVESI, 1999).

A amilase é uma enzima de interesse comercial e é utilizada na indústria alimentícia para fermentação, na indústria de papel e têxtil proporcionando maior resistência ao tear, pode ser usada ainda como: aditivos em detergente e sacarificação do amido (Marciano, 2009).

Para a produção de amilase é necessário uma fonte de carbono como: dextrina, lactose, amido solúvel entre outros, que podem ser substituídos por produtos agrícolas de baixo custo como: arroz, milho, trigo, cevada, mandioca entre outros, gerando uma economia ao processo produtivo, com isso procura-se aumentar a produção dessa enzima em fungos e bactérias. (OLIVEIRA et al, 2007).

A análise de amostras de solo de diferentes Áreas de Preservação Permanente (APP) e Mata Ciliar da região de Araçatuba demonstrou que, embora as características dos solos sejam distintas entre as áreas analisadas, todas apresentaram microrganismos que produziram e secretaram a amilase.

Quanto maior for a biodiversidade de uma determinada região para a análise de solo, maior quantidade de microrganismos que secretam a enzima amilase, ou seja, solos preservados apresentaram melhor índice de atividade enzimática.

O Brasil é conhecido mundialmente pela sua grande biodiversidade tanto em relação a fauna, flora, recursos naturais e minerais com benefício monetário. Os dados obtidos no presente trabalho demonstram que o solo também apresenta uma grande diversidade de microrganismos, dos quais alguns apresentam um grande potencial na obtenção de enzimas de interesse comercial.

\section{REFERÊNCIAS BIBLIOGRÁFICAS}

BULL, A.T.; WARD, A.C. \& GOODFELLOW, M. Search and discovery strategies for biotechnology: the paradigm shift. Microbiology and Molecular Biology Reviews, 64(3): 573-606. 2000. 
Marciano, S. L. Seleção de microrganismos do solo produtores de enzimas de interesse industrial, artigo publicado 12/05/2009.

MOREIRA, F. M. S.; SIQUEIRA, J. O. Microbiologia e bioquímica do solo. Lavras: Universidade Federal de Lavras, 2006, 729 p.

MOREIRA, F. M. S., SIQUEIRA J. O. E BRUSSARD L. Biodiversidade do solo na amazonia e outros ecossistemas brasileiros. Ed UFLA. 2008.

OLIVEIRA, A. N.; OLIVEIRA, L. A.; ANDRADE, J. S.; JUNIOR, C. Enzimas Hidrolíticas Extracelulares de isolados de Rizóbia nativos da Amazônia centra, Amazonas, Brasil ${ }^{1}$. Ciência e Tecnologia de Alimentos, Campinas, v. 26, n. 4, p. 853-860, out./dez, 2006.

OLIVEIRA, A. N.; OLIVEIRA, L, A.; ANDRADE, J. S.; JUNIOR, C, Produção de Amilase por Rizóbios, usando farinha de pupunha como substrato: Ciência e Tecnologia de Alimentos, Campinas, v. 27, n. 1, p. 61-66, jan./mar, 2007.

PRIMAVESI, A. Manejo Ecológico do solo. São Paulo, 1999. 549 p.

PANDEY, A.; NIGAM, P.; SOCCOL, C.R.; SOCCOL, V.T.; SINGH, D.; MOHAN, R. Advances in Microbial Amylases. Biotechnology Applied and Biochemical, 31:135152. 2000.

STALEY, J. 1998. Microbial Diversity and the Biosphere. www.bdt.org.br/oea/sib/staley. 